\title{
Do the Catholic and Protestant Countries Differ by Their Tax Morale?
}

\author{
Vesa Kanniainen \\ University of Helsinki and HECER \\ and \\ Jenni Pääkkönen \\ University of Helsinki and HECER
}

Discussion Paper No. 145

January 2007

ISSN 1795-0562

HECER - Helsinki Center of Economic Research, P.O. Box 17 (Arkadiankatu 7), FI-00014 University of Helsinki, FINLAND, Tel +358-9-191-28780, Fax +358-9-191-28781, E-mail info-hecer@helsinki.fi, Internet www.hecer.fi 


\title{
Do the Catholic and Protestant Countries Differ by Their Tax Morale?*
}

\begin{abstract}
The paper presents a model where illegal shadow production arises from tax evasion. The equilibrium size of the shadow production is determined by consumer moral valuations, possibly affected by the inherited culture or religion. The implications of the model are tested in the OECD data on groups of countries for two regimes 1979-1992 and 19922003. Evidence is found on a link between tax morale and shadow markets. No evidence, however, is found to support the view that the tax morale differs between the Catholic South and Protestant North in Europe. The results suggest that the earlier studies have overestimated the size of the shadow economies and that there has been a regime switch in the evolution of the shadow economies during the early 1990 s.
\end{abstract}

JEL Classification: C23, D43, H26, L13

Keywords: shadow economy, tax evasion, morality

Vesa Kanniainen

Department of Economics, University of Helsinki P.O. Box 17 (Arkadiankatu 7) FI-00014 University of Helsinki FINLAND

e-mail: vesa.kanniainen@helsinki.fi
Jenni Pääkkönen

Department of Economics University of Helsinki P.O. Box 17 (Arkadiankatu 7) FI-00014 University of Helsinki FINLAND

e-mail: ienni.paakkonen@helsinki.fi

* The authors like to thank Trevor Breusch, Vidar Christiansen, Panu Poutvaara, Agnar Sandmo and Peter Schmidt for their helpful comments. Financial support from Yrjö Jahnsson Foundation is gratefully acknowledged. 


\section{Introduction}

One of the most influential analyses of the links between economy, religion and morality has been Max Weber's The Protestant Ethic and the Spirit of Capitalism from 1904. The popular view - though an imprecise one - is that it has been the protestant ethics which has been benign to work ethic, having promoted the success of capitalism. Such a proposition may also be translated into an empirical prediction on how people are attached to different religion value illegal economic activities. It is indeed often suggested that the shadow markets are larger in the Mediterranean countries than, say in the northern welfare states, cf. Schneider (2004). His results suggest that the typical size of the shadow economy relative to GDP in the OECD countries has varied between 8.4 per cent (the US) and 28.2 per cent (Greece) in 2002-2003. A recent study by Alm and Torgler (2006) show that there are cultural differences regarding the tax morale across countries. They suggest that the northern Europeans have higher tax morale than the southern Europeans. In addition, they suggest that the Romanic countries have a higher tax immorality than most other countries. These results are in line with Kirchgässner (1999) who argues that historically in North Europe, the state and religious authority were largely held by one person and offences against the state were therefore also religious offences (and consequently a sin). Cross-country survey data for 1960 through 1978 suggests that the country-level "tax immorality" index has increased during that period, cf. Weck (1983). Though the more recent evidence by Alm and Torgler (2006) on other economies is somewhat mixed, many empirical papers indicate that the motive and incentives to evade taxes have increased (Schneider (2004)) over the past decades.

Can a religious (or other cultural) denomination be a plausible explanation for differences in tax morale? Some cultural differences allow one to ask this question. For example, in the southern catholic countries, religion has a built-in forgiveness tradition. One is tempted to suggest that this supports an equilibrium where the social punishment of, say tax evasion, can have a different meaning than in the protestant countries. Combining the evidence from the four waves of the World Values Surveys, we have learned that those belonging to a religious denomination are on average more likely to disapprove such behavior as cheating on taxes, claiming government benefits when not allowed, and accepting bribes. However, the Protestants are more likely to be even more stringent on these values than the Catholics. Moreover, when the proportion of the population belonging to a religious denomination is used a yardstick, countries form natural groups of the catholic South and the protestant North. In both country groups, the proportion of the members of church in the population varies between 80 - 95 per cent while 76 - 90 per cent of those were members of the dominating religion in that country.

Our paper introduces a model of consumers and entrepreneurs who value their moral code but are inherently opportunists in a sense that their morality is priced in market transactions. Then we use country data classified according to the dominating religious denomination to study tax morale and shadow markets. Other country groups are included to provide reference groups and facilitate the comparison to the previous studies.

The theory of tax evasion goes back at least to Allingham and Sandmo (1972). Subsequently, literature on social norms, punishment and tax evasion has been growing. On moral norms, Macaulay (1963) suggests that people behave honestly because honesty is rewarded 
and defection punished in future transactions. Brekke et al. (2003) propose a model where a consumer's self-image can only be improved by striving towards what she truly believes to be morally right. Then the benefits of good self-image will be traded against the costs. This idea is replicated by Johansson-Steman et al. (2005). Reciprocity is first mentioned by Kandori (1992), who suggest that social norms work to support efficient outcomes also in infrequent transactions where agents change their trading partners over time ${ }^{1}$. Fehr and Gächter (1998) consider Homo reciprocan as a norm enforcer. They summarize a number of experimental studies suggesting that a minority of people, between 20 per cent and 30 per cent, do not reciprocate and behave in a completely selfish way. More recently, Fehr and Gächter (2002) indicate that people are willing to invest in public goods, as long as they have the possibility to inflict punishment on those who free ride on the co-operation. Also Seinen and Schram (2004) suggest that cooperative action is rewarded by a third actor and that group norms develop. Anderberg (2006) has considered the matching problem between the market participants.

Baldry (1987) suggested that there are moral costs to cheating and that moral feelings have to be incorporated in the theory of tax evasion. Following this line of argument, Gordon (1989) incorporates social norms into the evasion decision assuming that the utility cost to evasion increases in the proportion of taxpayers who do not evade. The experiment by Myles and Naylor (1996) confirm a tax evasion model where a social custom utility is derived when taxes are paid honestly and a conformity payoff from adhering to the standard pattern of social behavior ${ }^{2}$. The results of Orvaska and Hudson (2002) suggest that evasion is condoned by a large proportion of the population though people appear to be deterred from tax evasion by the consequences of being caught.

Our paper contributes to the literature on tax morale and shadow markets. ${ }^{3}$ In our model, entrepreneurs provide their services to consumers through the legal or an illegal market. Values are determined in the market. The tax morale is reflected in the difference in the private valuation of legal and illegal transactions, arising from the social stigma and lack of self-respect from tax evasion. ${ }^{4}$ A legal producer benefits from consumers' moral aspirations which provides a compensatory mechanism for the tax to be paid. An illegal producer avoids the tax and can contract with the consumers visiting the shadow market in a lower price. It is not that in equilibrium all potential entrepreneurs are active. They have an outside option in terms of a government transfer when choosing unemployment. Tax

\footnotetext{
${ }^{1}$ The reasons for non-opportunistic behavior have been extensively discussed by biologists. Hamilton (1964) introduced the notion of kin selection and Trivers (1971) a more general view of reciprocal altruism. Wilson (1975) represents a comprehensive document of co-operative behavior among animals. Frank (1988) argued convincingly that the ability of people to behave non-opportunistically serves as a helpful commitment device facilitating beneficial relations like joint ventures. Binmore (1998) is a more recent contribution to the theory of how norms are formed.

${ }^{2}$ Falkinger (1995) notes that perceived fairness and equity of the political and economic system increases the bad conscience of evaders. Fortin et al (2004) find that perceived unfair taxation may lead to increased tax evasion.

${ }^{3}$ Our model highlights the conflict between opportunistic private incentives and collective values and norms. Some studies in the sociological literature explain crimes as an outcome of evolutionary interplay between productive and expropriative strategies, cf. Cohen and Machalek (1988) and Vila and Cohen (1993).

${ }^{4}$ Hausman and McPherson (1993) have provided a review of why and how morality influences economic outcomes. Cf. Frank (1987) for a pioneering analysis of honesty and dishonesty.
} 
evasion results in a fiscal externality in the financing of public goods. Public goods have the property that they enhance the private productivity of each entrepreneur. The tax rate chosen by a revenue-maximizing government hinges upon the tax morale of people in the economy. The welfare effects of shadow economy are ambiguous. ${ }^{5}$

By its intrinsic nature, the shadow economy is hidden. Causal models which incorporate latent variables have earlier been used to estimate the magnitude of the shadow economy by Giles and Tedds (2002) and Dell'Anno and Schneider (2003) among others. The previous studies which use the MIMIC approach have been, however, evaluated critically by Hill (2002), Smith (2002) and Breusch (2005a,b). The MIMIC model assumes that the connections that the indicator variables have with the causal variables are solely carried through the latent variable. This is perhaps the most severe problem identified. The specifications used by the existing studies indeed assume that there are no direct links between the cause variables and the indicators - an assumption which is not likely to hold. Unlike the earlier studies, we include also the direct effects between the causes and indicators.

We report three major results. First, our data reject the hypothesis that countries with a different religious background exhibit different shadow economies. Second, our results suggest that the shadow markets are much smaller than estimated earlier. The main reason for the substantive difference is that, we have included the direct effects from the cause variables to the indicators. Third, our results support a view that there has been a regime switch in the evolution of the public sector in the early 1990s and that in these regimes, the evolution of the shadow economies is different.

The road map of our paper is that we develop our theoretical model in Section 2. The model is estimated in Section 3 which reports the econometric results. Section 4 concludes.

\section{Model}

\subsection{Tax Morale}

To fix the ideas, we consider an economy where consumer services can be bought either in a legal or an illegal market. The mass of consumers is normalized to unity. The number of producers is normalized to $\eta$, where $\eta>0$. Each consumer buys at most one service. Each producer can service several buyers. Legal producers are subject to a tax, $\tau>0$. Illegal producers can contract with the buyers on a lower price and abstain from paying the tax.

People are different in terms of their moral aspirations. The consumer with the highest moral standard values the transactions with a legal producer by $\alpha_{1}$ and the transactions with an illegal producer by $\alpha_{2}$ where $\alpha_{1}>\alpha_{2}>0$. Valuations may differ for cultural or religious reasons between different populations (say, countries). Deviation from the legal

\footnotetext{
${ }^{5}$ Earlier, Davidson, Martin and Wilson (2003) have suggested that shadow transactions may increase welfare. By allowing agents to self-select into the black market, the government can in their model target tax breaks to transactions involving low-quality goods. We also notice that shadow markets may enhance welfare by limiting the pricing power of incumbent firms and by controlling tax collection. Thus the proponents of the view of governments as revenue-maximizing Leviathans, which use resources inefficiently, would welcome the shadow economy.
} 
norm results in the stigma or loss of self-respect. The rest of consumers are arranged in a linear ordering with declining valuation.

Thus, if the consumer $i$ buys from the legal and consumer $j$ from an illegal producer in a given population, their net utilities are

$$
u^{i}=\alpha_{1}(1-i)-p_{1} ; \quad v^{j}=\alpha_{2}(1-j)-p_{2} ; \quad \alpha_{1}>\alpha_{2}>0,
$$

where $p_{1}, p_{2}$ are the market prices of the legal and illegal products, yet to be determined.

While consumers are affected by the money they have to spend, entrepreneurs are affected by the money they can earn. The legal and illegal outputs are denoted by $x_{1}$ and $x_{2}$ and the production is subject to increasing costs. Public goods denoted by $g$ will enhance private productivity. Inactive entrepreneurs are entitled to a government transfer, $\delta>0$, representing an opportunity cost. The utility function of the entrepreneurs are taken to be

$$
U^{l}=\alpha_{1}(1-l) \pi_{1} ; \quad V^{h}=\alpha_{2}(1-h) \pi_{2},
$$

where the profits of the legal and illegal entrepreneurs, $l$ and $h$, are ${ }^{6}$

$$
\pi_{1}=p_{1} g x_{1}-\frac{1}{2} x_{1}^{2}-\tau ; \quad \pi_{2}=p_{2} g x_{2}-\frac{1}{2} x_{2}^{2} .
$$

It will turn out that the equilibrium is independent of the moral standard of the producers. The entrepreneurs are price-takers and the outputs are solved from the first-order conditions to be

$$
x_{1}=g p_{1} ; \quad x_{2}=g p_{2} .
$$

With free entry to both sectors, market prices have to adjust to eliminate the rents. From $\pi_{1}=\pi_{2}=\delta$, where the unemployment compensation is used to measure the opportunity cost. We obtain

$$
p_{1}=\frac{\sqrt{2(\tau+\delta)}}{g} .
$$

Similarly,

$$
p_{2}=\frac{\sqrt{2 \delta}}{g}
$$

Therefore, the illegal price is lower than the legal price as the private benefits from tax evasion are split between the buyers and the legal entrepreneurs.

To solve for the legal and illegal production, denote by $m$ the marginal consumer who is indifferent between buying the legal and the illegal product. Similarly, denote by $n$ the consumer who is indifferent between buying the illegal product and none. It can be proved that the consumers $(0, m)$ buy the legal product and consumers $(m, n-m)$ by the illegal product. Thus, the net utility of the consumer $n$ is

\footnotetext{
${ }^{6}$ It is assumes that the illegal producers are not able to exploit government transfers if they are active. This assumption is not fully realistic and it leads to that the size of the illegal markets is somewhat underestimated in our theoretical model. It is, however, a trivial matter to include the exploitation of government transfers by the illegal producers by introducing in $\pi_{2}$, the profit, an opportunity cost say $\mu \delta, \mu<1$ instead of just $\delta$.
} 


$$
\alpha_{2}(1-n)-p_{2}=0
$$

or

$$
n=1-\frac{p_{2}}{\alpha_{2}}
$$

It holds for the consumer $m$,

$$
\alpha_{1}(1-m)-p_{1}=\alpha_{2}(1-m)-p_{2}
$$

or

$$
m=1-\frac{p_{1}-p_{2}}{\alpha_{1}-\alpha_{2}} .
$$

Then, the size of the shadow sector, measured by the number of consumers is

$$
n-m=\frac{p_{1}-p_{2}}{\alpha_{1}-\alpha_{2}}-\frac{p_{2}}{\alpha_{2}} .
$$

We find

Lemma 1 The condition for the existence of the shadow sector is

$$
\frac{\alpha_{2}}{\alpha_{1}}>\sqrt{\frac{\delta}{\tau+\delta}}
$$

Moreover, as comparative static results, we find that the lower is the tax morale, i.e. the smaller is $\alpha_{1}-\alpha_{2}$ and the greater is the tax rate $\tau$, the bigger is the shadow economy, $n-m$.

Also,

Lemma 2 The condition for the legal sector to survive is $m>0$, or

$$
\alpha_{1}-\alpha_{2}>\frac{1}{g}(\sqrt{2(\tau+\delta)}-\sqrt{2 \delta}) .
$$

According to Lamma 2, tax morale has to be sufficiently great to sustain legal markets. There is also a ceiling to the tax rate

$$
\tau<\frac{1}{2}\left(g\left(\alpha_{1}-\alpha_{2}\right)+\sqrt{2 \delta}\right)^{2}-\delta .
$$

\subsection{Laffer-curve and Tax Morale}

Consider a revenue-maximizing Leviathan government, extracting a share $\lambda>0$ for its own consumption. It maximizes $\lambda T$. The timing in our model is such that the government forms expectation on the tax morale and decides on the tax rate in stage 0 . The extent of shadow markets is determined conditionally on the tax morale developed. In the equilibrium with 
shadow economy, the number of tax paying entrepreneurs is $\frac{m}{x_{1}}=\frac{m}{\sqrt{2(\tau+\delta)}}$. Then, the tax revenue (Laffer-curve) is

$$
T=\left[1-\frac{1}{\alpha_{1}-\alpha_{2}} \frac{1}{g}(\sqrt{2(\tau+\delta)}-\sqrt{2 \delta})\right] \frac{\tau}{\sqrt{2(\tau+\delta)}} .
$$

Developing the derivative

$$
\partial T / \partial \tau=-\tau+\left[g\left(\alpha_{1}-\alpha_{2}\right)-\sqrt{2(\tau+\delta)}+\sqrt{2 \delta}\right] \frac{\tau+2 \delta}{\sqrt{2(\tau+\delta)}},
$$

We see that at the origin, $(\partial T / \partial \tau)_{\tau=0}=g\left(\alpha_{1}-\alpha_{2}\right) \sqrt{2 \delta}>0$. Thus, the Laffer-curve is increasing at the origin. Developing the second derivative,

$$
\partial^{2} T / \partial \tau^{2}=-\frac{1}{2(\tau+\delta)^{2}}\left[-\frac{5 \tau+4 \delta}{2}+\frac{\left[g\left(\alpha_{1}-\alpha_{2}\right)-(\sqrt{2(\tau+\delta)}-\sqrt{2 \delta})\right](3 \tau+4 \delta)}{2 \sqrt{2(\tau+\delta)}}\right] .
$$

At the origin,

$$
\partial^{2} T / \partial \tau^{2}=-\frac{1}{\delta}\left[\frac{g\left(\alpha_{1}-\alpha_{2}\right)}{\sqrt{2 \delta}}-1\right] .
$$

This is negative when $\frac{g\left(\alpha_{1}-\alpha_{2}\right)}{\sqrt{2 \delta}}>1$ or when $\alpha_{1}-\alpha_{2}>p_{2}$. We assume this to be the case as it just states the condition that the tax morale is strong enough. Denote the tax rate which maximizes the revenue by $\tau^{*}$. The remaining question is whether the $\tau^{*}<\tau^{\max }$ where $\tau^{\max }$ is the maximal tax rate available (making the tax revenue approach zero). It was solved above to be

$$
\tau^{\max }=\frac{1}{2}\left(g\left(\alpha_{1}-\alpha_{2}\right)+\sqrt{2 \delta}\right)^{2}-\delta .
$$

At this rate rate, $\alpha_{1}-\alpha_{2}=\frac{1}{g}(\sqrt{2(\tau+\delta)}-\sqrt{2 \delta})$ making the first derivative of Laffer curve $g\left(\alpha_{1}-\alpha_{2}\right)=\sqrt{2(\tau+\delta)}-\sqrt{2 \delta}$ negative. Subject to the condition, $g\left(\alpha_{1}-\alpha_{2}\right)>\sqrt{2 \delta}$, we have proved

Proposition 3 The economy faces a concave Laffer curve with tax revenue maximizing tax rate satisfying

$$
\tau^{*}<\tau^{\max } .
$$

A small valuation difference $\alpha_{1}-\alpha_{2}$, points to low tax morale whilst the large difference points to greater tax morale. Does an increase tax morale, $\alpha_{1}-\alpha_{2}$ enhance the government's ability to collect tax revenue? Yes, it does. By straightforward derivation, one can show that $\partial T /\left(\alpha_{1}-\alpha_{2}\right)>0$ and that $\partial \tau^{*} /\left(\alpha_{1}-\alpha_{2}\right)>0$ for any given $g$. The latter conclusion follows from $\partial \tau^{\max } / \partial\left(\alpha_{1}-\alpha_{2}\right)>0$. This means that with increased tax morale, the Laffer curve moves up and to the right. Allowing $g$ adjust is more complicated but the result can be expected to hold.

We can endogenize the supply of public goods through the government budget. The entrepreneurs who are not active are entitled to a government transfer. The mass of buyers 
in the legal and illegal sector is $m$ and $n-m$ and the mass of customers per entrepreneurs is $x_{1}$ and $x_{2}$, respectively. Thus, the mass of entrepreneurs in two sectors is $\frac{m}{x_{1}}$ and $\frac{n-m}{x_{2}}$. Therefore, the mass of entrepreneurs collecting the government transfer $\delta$ is

$$
u=\eta-\frac{m}{x_{1}}-\frac{n-m}{x_{2}} .
$$

Then the government budget satisfies.

$$
T=g+u \delta \text {. }
$$

From above, we know that with an increased tax rate, entrepreneurs' have to raise their price. A government planning a tax increase should be aware of the fact that this promotes the expansion of the shadow economy.

\subsection{Multiple Equilibria and Prisoner's Dilemma}

For a moment, consider the economy modelled above in a state without a shadow market. All producers are in the legal sector and pay the tax. There is no tax evasion and the tax collection generates tax revenue. It holds for the marginal consumer that $\alpha_{1}(1-m)-p_{1}=0$. Therefore,

$$
m=1-\frac{p_{1}}{\alpha_{1}} .
$$

The output decision of the legal firm is the same as above and so is the zero-profit condition for entrepreneurs. Therefore, the legal price is the same as above. The marginal consumer in the legal market is, however, now different. In the absence of the illegal market, there are more legal customers provided that the incentive condition for the existence of the illegal market $\frac{\alpha_{2}}{\alpha_{1}}>\sqrt{\frac{\delta}{\tau+\delta}}$ holds. This means that the government's tax revenue is greater, too. The amount of unemployment compensation is such of equilibrium is

$$
\delta u=\delta\left(\eta-\frac{m}{x_{1}}\right)
$$

and the public goods to be supplied in such an equilibrium satisfy

$$
g=T-\delta\left(\eta-\frac{m}{x_{1}}\right)
$$

If each entrepreneur expects everyone else to contribute to the tax revenue and financing of public goods, the economy can settle down in a "good equilibrium". If each entrepreneur, however, expects that no one else will contribute to the tax revenue, the economy can settle down in a "bad equilibrium" with the substantially reduced supply of public goods. This is the equilibrium we studied above. Though no one wants the economy to settle down in the bad equilibrium every entrepreneur, however, has a private incentive to deviate as he can increase his profit by establishing shadow activities. This is easily established. A legal producer choosing output $x_{1}=g p_{1}$ optimally generates a profit $\pi_{1}=\frac{1}{2}\left(q p_{1}\right)^{2}-\tau$. Any producer can, of course, make a bigger profit $\pi_{2}=\frac{1}{2}\left(q p_{1}\right)^{2}$ by abstaining from the tax 
payment, provided no other producer follows. However, as every producer has this incentive, the economy will settle down in the bad equilibrium studied above. The good equilibrium is therefore subject to private opportunism and prisoners' dilemma. The economy will settle down in a bad equilibrium studied above and with the reduced supply of public goods. Thus, when $\frac{\alpha_{2}}{\alpha_{1}}>\sqrt{\frac{\delta}{\tau+\delta}}$, we have proved the following,

Proposition 4 Shadow economy arises as prisoner's dilemma.

\subsection{Towards Empirical Hypotheses}

The link between the size of the illegal market and the tax morale is found to be

$$
n-m=\frac{1}{g\left(\alpha_{1}-\alpha_{2}\right) \alpha_{2}}\left(\alpha_{2} \sqrt{2(\tau+\delta)}-\alpha_{1} \sqrt{2 \delta}\right) .
$$

Given the attitudes towards tax morale, it is now possible to trace the effects of government policies on the structure of the production sector including the shadow economy. We find that an increase in the tax rate increases the number of customers visiting the shadow market,

$$
\frac{\partial(n-m)}{\partial \tau}=\frac{1}{g\left(\alpha_{1}-\alpha_{2}\right) \alpha_{2}}\left(\frac{\alpha_{2}}{\sqrt{2(\tau+\delta)}}\right)>0
$$

We also find that ceteris paribus, an increase in public goods has the opposite effect. In particular, the elasticity of shadow demand with respect to the provision of public goods is unity,

$$
\frac{\partial(n-m)}{\partial g} / \frac{(n-m)}{g}=-1 .
$$

The public goods effect works through the output decisions by the producers.

Unemployment benefit, however, results in an ambiguous effect and it increases both prices,

$$
\frac{\partial(n-m)}{\partial \delta}=\frac{1}{g\left(\alpha_{1}-\alpha_{2}\right) \alpha_{2}}\left(\frac{\sqrt{2 \delta} \alpha_{2}-\alpha_{1} \sqrt{2(\tau+\delta)}}{\sqrt{2 \delta} \sqrt{2(\tau+\delta)}}\right) \gtrless 0 .
$$

Such results have descriptive value but make the issues ultimately empirical. There is a further complication when building the bridge between tax policies and shadow markets. The policy variables are inter-related though in a complicated way. Consider the government budget constraint. An increased tax rate has no direct impact on the shadow market. What is does in then first instance is to raise the equilibrium price in the legal market, $\partial p_{1} / \partial \tau>0$, making each legal producer bigger, $\partial x_{1} / \partial \tau>0$. However, the number of legal producers declines, $\partial\left(m / x_{1}\right) / \partial \tau<0$. (This follows from $\left.\partial m / \partial p_{1}<0\right)$. As a result, there will be more unemployment. Now, the number of illegal producers, $(n-m) / x_{2}$ will increase as $\partial(n-m) / \partial p_{1}>0$, reducing unemployment. Which of two effects on unemployment dominates? Evaluating the total effect, we find that

$$
\partial u / \partial \tau=\frac{1}{x_{1}}\left[-\frac{1}{g\left(\alpha_{1}-\alpha_{2}\right)}\left(\frac{1}{x_{1}}-\frac{1}{x_{2}}\right)+\frac{m}{2(\tau+\delta)}\right]>0,
$$


which follows from that $\frac{1}{x_{1}}-\frac{1}{x_{2}}<0$.

Suppose that the economy is settled at the top of the Laffer curve with the property that $\partial T / \partial \tau=0$. Thus, an increase in the tax rate cannot generate additional tax revenue. However, an increase in the tax rate increases the number of those eligible for unemployment compensation. As a result, in the case where the government budget constraint is strictly binding, the supply of public goods must be reduced when the economy is settled at the top of the Laffer curve.

Additional complications may arise from two sources. First, the economy may not be settled down at the top of the Laffer curve. Second, with access to public debt, the government may actually face a soft budget constraint.

Our paper asks whether one can identify differences in the tax morale among countries with different cultural backgrounds. For the reasons discussed in this section, we find appropriate to include various fiscal variables among the explanatory variables and to ask whether we can identify cross-country differences between the policy variables and indicators of the shadow economy. The truly exogenous parameter is our tax morale, measured by the valuation difference $\alpha_{1}-\alpha_{2}$. Our model in this section has shown in which way the tax morale determines the size of the shadow economy. It also provides a description of how the shadow economy will respond to the government policies in terms of taxes, public goods and transfers. The empirical section below estimates these relations taking that the tax morale operates as the transmission mechanism between those policies and shadow markets. Differences in the response of the shadow markets to those policies is taken as an indication of differences in tax morale in various countries.

\section{Empirical Analysis}

\subsection{Method}

The shadow activities are unobservable. This represents a challenge for the econometric testing of the theoretical hypotheses. The problem, however, is quite common in economics ${ }^{7}$ and can be coped by SEM (structural equation modeling). The estimation theory was originally developed by Zellner (1970) and Jöreskog and Goldberger (1975) though a number of authors have contributed to this literature ${ }^{8}$. This method has earlier been used to estimate the magnitude of the shadow economy by Frey and Weck-Hanneman (1984), Aigner, Schneider and Ghosh (1988), Giles and Tedds (2002) and Dell'Anno and Schneider (2003) among others.

A latent variable is a random variable whose realizations are hidden from an observer. Even though it may have operational implications for relationships among observable variables. The observable variables may appear as the causes of the latent variable as well as

\footnotetext{
${ }^{7}$ According to Wansbeek and Meijer (2001), a theoretical variable concerned is purely a mental construct that does not strictly correspond to a variable that can be observed in practice. The examples of such variables are human capital, the productivity of a worker, consumer satisfaction or as in this study, illegal activity. The "causes" may be viewed as the instruments in IV-approach (Goldberger (1972) and Angrist et al. (1996)).

${ }^{8}$ The special issue of the Journal of Econometrics (1983) is devoted to this approach. See also Aigner et al (1984). For textbook presentations, one can refer to Aigner and Goldberger (1979), Keiding et al. (2004) and Schumacker and Lomax (2004).
} 
indicators of latent variable. A structural model links the observed causes to the unobserved variable(s) and the measurement model links the latent variable(s) to observed indicators. Together these models compress as a structural equation model (Figure 2). The MultipleIndicator-Multiple-Cause (MIMIC) model is a version of SEM with only one latent variable.

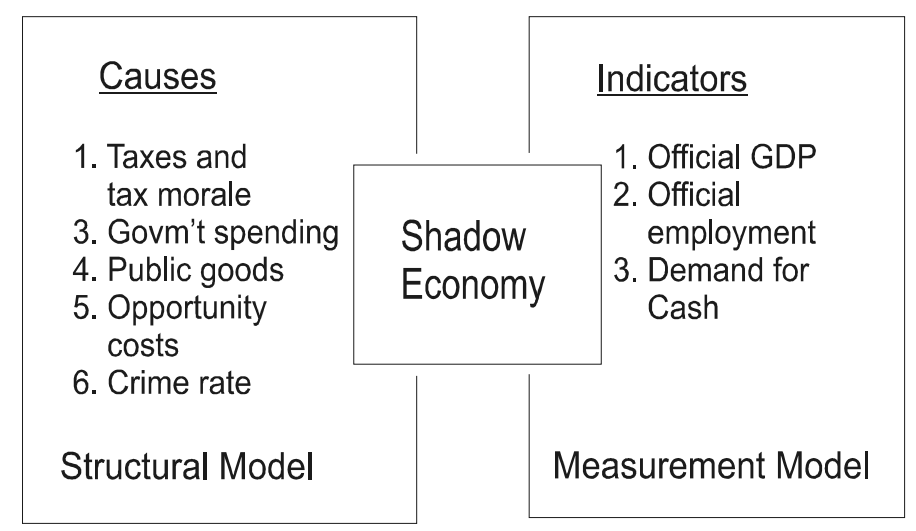

Figure 2: Modeling the shadow economy

The studies using the MIMIC model to estimate the shadow economy have been criticized by Hill (2002), Smith (2002) and Breusch (2005a,b). For example, Hill (2002) states on Giles and Tedds (2002) that there is no theory behind the estimated model, a characteristic that is common for most, if not all, of these studies. In addition, he notes that the causal variables and the indicator variables must correspond closely enough to latent variable so that the researcher can be confident that the latent variable is identified in the estimation. Also the reliability of the results is difficult to judge as there are no reliable alternative methods. He concludes, however, that in the end, the MIMIC approach to the underground economy is valid. Hills' critique is echoed by Smith (2002) who argues that as the size of the shadow economy must be calibrated by using "outside information", the "other source" for obtaining the benchmark becomes critical.

The most challenging critique is, however, due to Breusch (2005a,b). He points out that the previous studies have not documented the transformations, making the replication of results difficult. Errors are also made when the predictions of the latent variable are formed, as the parameter estimates are applied to the original untransformed data. Most critically, the MIMIC model assumes that the relations that the indicator variables have with the causal variables are solely carried through the latent variable. In other words, the specifications used by the existing studies deny any direct effects between the cause variables and the indicators. This criticism is a valid one but it can be handled.

Suppose throughout that all variables are measured around their respective population means. Thus, the intercept is omitted. The structural model assumes that the latent variable $y^{*}$ is determined as

$$
y^{*}=\alpha_{1} q_{1}+\alpha_{2} q_{2}+\ldots+\alpha_{k} q_{k}+\epsilon,
$$

where the observable exogenous causes $q_{1}, \ldots, q_{k}$ are obtained from the theoretical model and where $\epsilon$ is the disturbance term. 
In our measurement model, the latent variable determines, together with (some) cause variables and disturbances $u_{1}, \ldots, u_{m}$, the set of observable indicators $y_{1}, \ldots, y_{m}$

$$
y_{1}=\beta_{1} y^{*}+\sum_{i=1}^{k} \gamma_{1 i} q_{i}+u_{1}, \ldots, y_{m}=\beta_{m} y^{*}+\sum_{i=1}^{k} \gamma_{m i} q_{i}+u_{m} .
$$

The earlier studies imposed the constraint $\gamma_{j i}=0$ for all $j, i$. We, however, estimate the specification which allows for some non-zero $\gamma^{\prime}$ s, i.e. allows for direct effects. ${ }^{9}$

The indicator variables are assumed to reflect the evolution both of the unobserved latent variable and the cause variables and are thought to covariate with them. In vector-form

$$
\begin{aligned}
y^{*} & =\alpha^{\prime} q+\epsilon, \\
y & =\beta y^{*}+\gamma q+u,
\end{aligned}
$$

with $E[\epsilon]=0, E[u]=\left[\begin{array}{lll}0 & 0 \ldots & 0\end{array}\right]^{\prime}, E[\epsilon u]=\left[\begin{array}{lll}0 & 0 \ldots & \ldots\end{array}\right]^{\prime}, E\left(\epsilon^{2}\right)=\sigma^{2}$ and $E\left(u \times u^{\prime}\right)=\Theta^{2}$.

Substituting, we obtain the reduced-form relation

$$
y=\left(\beta \alpha^{\prime}+\gamma\right) q+\beta \epsilon+u=\Pi^{\prime} q+v,
$$

where the reduced-form coefficient matrix is $\Pi=\alpha \beta^{\prime}+\gamma^{\prime}$ and where the reduced-form disturbance vector, $v=\beta \epsilon+u$ has covariance matrix $\Omega=E\left(v v^{\prime}\right)=\sigma^{2} \beta \beta^{\prime}+\Theta^{2}$.

We estimate the coefficient matrix $\Pi$ in equation (11) which contains only observable variables. Estimation of structural parameters is computed using maximum likelihood techniques, making use of the restrictions implied in both the coefficient matrix $\Pi$ and the covariance matrix of the error term $\nu$. Such restrictions are needed because without them the model would not be identified. With all direct effects included, even those restrictions would not suffice to identify the model. To determine $\alpha$ and $\beta$, one of the factor loadings has to be fixed (anchoring). The restrictions for direct effects, i.e. restrictions that some of the $\gamma$ 's are zero, are easily found using our theoretical model. If there was no theory behind the estimations, one could not convincingly argue that some of the $\gamma$ 's should equal zero, leaving the model undetermined.

\subsection{Hypotheses and Data}

In this section, we analyze empirically how the indicators of the shadow economy are affected by the government policies. For the empirical analysis, we identify five cause variables and three indicators. The hypotheses will be tested using annual data for 21 industrialized OECD countries for 1979 through 2003. All variables, except the nominal interest rate, are measured as growth rates per annum. Thus, our latent variable is the rate of growth of shadow economy, instead of being the size of the shadow economy relative to the official $\operatorname{GDP}\left(x_{i} / x_{l}\right)$ as in previous studies.

\section{Cause variables}

1. Total tax revenue $(\tau)$, growth rate. The higher the tax burden, the greater the shadow economy. It thus reflects both, the tax evasion effect of homo oeconomicus and the sentiments of homo moralis.

\footnotetext{
${ }^{9}$ We thank Bengt Muthen for indicating us how to accomplish the estimation task.
} 
2. Government consumption $(g)$, growth rate as a measure of the public good. Growth of the public good is expected to increase the growth of the shadow economy.

3. Government transfers $(\delta)$, growth rate. We expect transfer payments to reduce the incentives to work in the shadow economy.

4. Crime rate $(k)$, growth rate. Proxy of the general morale or social capital in the society. A high crime rate either reflects low social capital or an increased rate of crime reporting. The former has a positive the latter a negative effect on the illegal economy.

5. Nominal short-term interest rate $(r)$. An increase in interest rate increases the opportunity costs of holding money thus reducing the shadow transactions.

\section{Indicators}

1. Real GDP per capita, growth rate, $(x)$. It is not obvious whether there should be a positive or a negative relationship between official and shadow economy. It is conceivable that when the official economy is booming, so is the unofficial sector and vice versa. On the other hand, the relationship might also be the other way round, i.e. that a boom in the official sector is associated with a slowdown of the illegal sector. Based on our theoretical model we expect a positive association between the shadow economy and the official economy.

2. Labor force participation rate in the official sector, $(l)$, growth rate. Similar arguments hold for the relationship between the shadow economy and the labor force participation rate, as was for the GDP. We expect a positive association between the shadow economy and the labor force participation rate.

3. Real currency in circulation per capita, $(m)$, growth rate. This variable measures changes in payment habits. The greater growth of cash payments reflects the greater growth of the shadow transactions.

\subsection{Estimation Results}

Preliminaries All variables are measured as growth rates per annum (see Appendix A), except the nominal interest rate which is measured as $\log \left(1+r_{t}\right)$. On the basis of LevinLin (1993) and Im-Pesaran-Shin (2003) tests we conclude that the series are stationary. In addition, the variables appear to be non-normal, hence we use the adjusted ML-estimation method and report the adjusted test statistics. Moreover, when we scrutinize the public sector variables, a break appears in the data which points to two regimes. Hence, we split the data into two periods instead of fitting the model in the full sample. We call the first period the regime of the public sector growth (1979-1992) whilst the second period is called the regime of a mature public sector (1992-2003). In addition, we notice that there are differences among countries according to their historical, regional and cultural heritage, which might be reflected in the magnitudes of the shadow economy. We thus decided to group the countries with respect to their geographical location and by the dominating religion. 
Two indicators of the religious orientation were taken into account. The first one is the proportion of the citizens of a country belong to a religious denomination. The second one is the dominating religious denomination of a country. Using these two measures, there are two distinctive groups: the Catholic South (CS) with the membership ratios of 80 - 95 per cent and the Protestant North (PN) with the membership ratio of 80 - 90 per cent. In addition, the German-speaking (GER) countries are assumed to share the same cultural heritage. Remaining countries form two control groups, the Rest of the Europe (RoE) and the Rest of the World (RoW). We first estimate the equations for regimes I and II in the pooled data. Then we partition the data in the groups and estimate the equations for regimes I and II.

Results To identify the model, we must impose two kinds of restrictions as discussed above. Firstly, we must fix one of the factor loadings hence we impose the restriction $\beta_{1}=1$, which suggest that an increase in the shadow economy increase real GDP per capita, both in growth terms. Secondly, we must set some of the direct effects to zero while we seek the parsimonious representation of the model. This process is guided by $t$-statistic and the fit indices. After eliminating the insignificant direct effects one by one the ones that remain are as follows. The interest rate for the currency; the transfers, public goods and interest rate for the labor force participation rate. The diagnostic test results for the pooled data are presented in Table 1. All the diagnostic tests, with the exception of TLI in regime I, support the model in both periods and that there is a latent variable. ${ }^{10}$

The first period values of $R^{2}$ are 0.23 to the growth of the currency, 0.10 to the growth of the labor force participation rate, undefined of the growth of GDP ${ }^{11}$ and 0.25 to the latent variable. For the latter period, the $R^{2}$ 's are 0.01 to the currency, 0.22 to the labor force, 0.51 to the GDP and 0.84 to the latent variable.

Table 1. The fit indices for pooled data.

\begin{tabular}{|l|l|l|l|l|}
\hline & \multicolumn{2}{|l|}{$1979-1992$} & \multicolumn{2}{l|}{$1992-2003$} \\
\hline Tests of model fit & Value & $p$-value & Value & $p$-value \\
\hline$\chi^{2}$-test / degrees of freedom & $14.07 / 6$ & 0.029 & 8,261 & 0.219 \\
$\chi^{2}$-test model comparison & $192.5 / 18$ & 0.000 & 226.191 & 0.000 \\
CFI & 0.954 & n.a. & 0.989 & n.a. \\
TLI & 0.861 & n.a. & 0.967 & n.a. \\
SRMR & 0.029 & n.a. & 0.020 & n.a. \\
\hline
\end{tabular}

Our pooled estimation results are presented in Table 2. To solve for the vector of the parameters, we normalize the coefficient of the growth of GDP equal to one ${ }^{12}$. Then for the first period an estimate for $\beta$ for the growth of the currency is 0.79 with the $t$-statistics of 3.702, which is highly significant. The estimate for the growth of labor force is 0.093 and insignificant. In the second period, we find that the growth of the currency looses its significance as an indicator $(\beta=0.398)$ whilst the labor force becomes more significant

\footnotetext{
${ }^{10}$ More detailed description about how the direct effects were eliminated and about the cut-off values for fit indices in Appendix B (See also Schumacker and Lomas (2004)).

${ }^{11}$ The matrix theta for the GDP was not positive definite.

${ }^{12}$ The $R^{2}$ is the highest for the GDP therefore it is conceivable to fix the factor loading of the GDP as then the model iterates faster yielding the empirical estimates. Note that the remaining free parameters are solved subject to this constraint.
} 
$(\beta=0.605)$.

As to the direct effects, there indeed are significant ones. The interest rate variable is statistically significant for the demand for money in both regimes. In the first regime, also the transfers and the government consumption are important determinants for the growth of labor force participation rate. Clearly, it is true that direct effects must be "cleaned" when solving for the indirect effects.

Our main interest, however, lies on the estimates for $\alpha$ 's, as they reflect the effects of our presumed causes on the shadow economy. In both regimes, the public sector variables $g, \delta$ and $\tau$ appear significant although the magnitude of the parameter estimates change when we switch from the first regime 1979-92 to the other 1992-2003. The effect of the tax variable on the shadow economy becomes greater while the effect of transfer payments decreases. The effect of government consumption remains quite the same. It thus appears that the tax morale has worsened in the latter regime; neither do the transfer payments (having a negative effect) bribe people away from the shadow economy as much as they used to. In a sense, these results are unexpected. One would have thought that in the latter regime with a more "mature" public sector, these variables have become less significant.

We also find that the opportunity cost of holding cash has a negative and significant effect on the shadow economy. As the official economy has other means of payments, then the increased opportunity costs fall more on the illegal transactions. Comparing the estimated magnitudes of their elasticities it indeed appears that the illegal demand for money is more inelastic than the total demand for money. One should not, however, make too much out of this result, as our aim was not to estimate the demand for money; the "model" is not complete.

Table 2. Estimation results, with ${ }^{*},{ }^{* *}$ and ${ }^{\dagger}$ indicating 1\%, 5\% and $10 \%$ level of significance.

\begin{tabular}{|c|c|c|c|c|}
\hline & \multicolumn{2}{|c|}{ 1979-1992 } & \multicolumn{2}{|c|}{$1992-2003$} \\
\hline Causes & $\alpha$ & $t$-stat & $\alpha$ & $t$-stat \\
\hline$\tau$ & 0.158 & $5.280^{*}$ & 0.223 & $8.723^{*}$ \\
\hline$\delta$ & -0.247 & $-6.695^{*}$ & -0.147 & $-4.510^{*}$ \\
\hline$g$ & 0.106 & $1.893^{\dagger}$ & 0.127 & $3.638^{*}$ \\
\hline$k$ & -0.002 & -0.166 & 0.002 & 0.264 \\
\hline$r$ & -0.112 & -1.641 & -0.165 & $-3.850^{*}$ \\
\hline Direct effects & $\gamma$ & $t$-stat & $\gamma$ & $t$-stat \\
\hline \multicolumn{5}{|l|}{ on currency } \\
\hline by $r$ & -0.422 & $-4.764^{*}$ & -0.380 & $-2.374^{* *}$ \\
\hline on labor force & $\gamma$ & $t$-stat & $\gamma$ & $t$-stat \\
\hline by $\delta$ & -0.116 & $-3.273^{*}$ & -0.032 & -0.483 \\
\hline by $g$ & 0.183 & $3.401^{*}$ & 0.056 & 0.983 \\
\hline by $r$ & -0.083 & -1.212 & -0.038 & -0.603 \\
\hline
\end{tabular}

Our next step is to check whether there are differences in the parameter estimates among the country groups. The diagnostic test results for both regimes are presented in Table 3. This time the indices indicate poorer fit although they are slightly better in the latter period. The decrease in the fit might be due to the fact that we had to impose exactly the same structure for all groups, hence the model does not allow enough variation between the 
groups ${ }^{13}$. Also note that the vector of $\beta$ 's is forced to be the same across the groups. Only the vectors of $\alpha$ and $\gamma$ are allowed to differ. Then for the first period, the estimated coefficient for the growth of the currency is 1.397 with the $t$-statistics of 10.329 and for the growth of the labor force participation rate is 0.276 with the $t$-statistics of 3.034. Compared with the results obtained using pooled data, it appears that the vector of $\beta$ 's has changed drastically. In addition, we report the following $R^{2}$ 's for the equations of the latent variable: 0.75 for the German (GER) group, 0.74 for the Nordic (PN) group, 0.57 for the Mediterraneans (CS), 0.39 for the Rest of Europe (RoE) and 0.85 for the Rest of the World (RoW). With the exception of RoE, these are remarkably high. To save space, we do not report the $R^{2}$ 's for observed variables.

Table 3. Diagnostic test results for grouped data

\begin{tabular}{|l|l|l|l|l|}
\hline & \multicolumn{2}{|l|}{$1979-1992$} & \multicolumn{2}{l|}{$1992-2003$} \\
\hline Tests of model fit & Value & $p$-value & Value & $p$-value \\
\hline$\chi^{2}$-test / degrees of freedom & $177.0 / 46$ & 0.000 & 100.45 & 0.000 \\
$\chi^{2}$-test model comparison & $933.4 / 90$ & 0.000 & 672.75 & 0.000 \\
CFI & 0.845 & n.a. & 0.907 & n.a. \\
TLI & 0.696 & n.a. & 0.817 & n.a. \\
SRMR & 0.072 & n.a. & 0.057 & n.a. \\
\hline
\end{tabular}

The group results in the first regime are presented in the Table 4 . The direct effects continue to be significant. We first notice that the transfer payments variable has a significant impact on shadow transactions in all country groups although its magnitude varies quite a bit. It remarkably limits the size of the shadow economy in the German group while it has a much smaller effect in the group of the Mediterranean economies. We also notice that for German-speaking countries, the other cause variables have no impact what so ever on the growth of the shadow economy. This result might, at least partly, be due that the German mark was used as the black currency in the CEE-countries as well. For their shadow economies, the German government policy does not make the difference.

In the other extreme, we have the Nordic countries (PN), where the cause variables, with the exception of the crime rate, have all a statistically significant effect on the growth of the shadow economy. These countries, by the way, had quite closed and protected economies until the 1990's. A similar result, now with the exception of government consumption, applies to the Rest of the World countries (RoW). In that group, the crime rate has a negative effect on the shadow economy. Perhaps this reflects an increased probability of being caught. For Mediterranean countries (CS), we notice that government consumption has a positive effect on the shadow transactions. Does this finding suggest that people in those countries regard government consumption as waste by a Leviathan government? We also note that for the rest of Europe (RoE), the model does not fit well as the countries pooled in this group are rather heterogenous. Lastly we notice that as the differences across countries are quite remarkable, this casts a shadow to whether estimates obtained from pooled data are sensible. Let us first, however, take a look into the results from the latter regime.

\footnotetext{
${ }^{13}$ Note that there are 20 insignificant parameter estimates in the model, which weaken the model fit. If we take this into account and re-calculate the TLI, its value would be 0.82 in the first period and 0.92 in the latter period. The values for CFI would be 0.87 and 0.94 .
} 
Table 4. Group estimates in the first regime, 1979-92.

\begin{tabular}{|c|c|c|c|c|c|c|c|c|c|c|}
\hline \multirow{2}{*}{\begin{tabular}{|l|} 
\\
Cause \\
\end{tabular}} & \multicolumn{2}{|l|}{ GER } & \multicolumn{2}{|l|}{$\mathrm{PN}$} & \multicolumn{2}{|l|}{$\mathrm{CS}$} & \multicolumn{2}{|l|}{ RoE } & \multicolumn{2}{|l|}{ RoW } \\
\hline & & & & & & & & & & \\
\hline & $\alpha$ & $t$-stat & $\alpha$ & $t$-stat & $\alpha$ & $t$-stat & $\alpha$ & $t$-stat & $\alpha$ & $t$-stat \\
\hline$\tau$ & 0.01 & 0.15 & 0.20 & $4.07^{*}$ & -0.07 & -1.44 & 0.10 & 1.60 & 0.30 & $6.82^{*}$ \\
\hline$\delta$ & -0.44 & $-3.77^{*}$ & -0.29 & $-3.77^{*}$ & -0.13 & $-1.98^{* *}$ & -0.23 & $-3.21^{*}$ & -0.21 & $-5.19 *$ \\
\hline$g$ & -0.12 & -0.71 & 0.13 & $1.78^{\dagger}$ & 0.19 & $2.79^{*}$ & 0.07 & 0.55 & -0.10 & -1.28 \\
\hline$k$ & 0.03 & 1.22 & 0.02 & 0.69 & -0.03 & -1.10 & 0.00 & 0.00 & -0.06 & $-2.48^{* *}$ \\
\hline$r$ & 0.01 & 0.13 & -0.23 & $-2.12^{* *}$ & -0.34 & $-3.25^{*}$ & -0.02 & -0.20 & -0.13 & $-1.92^{\dagger}$ \\
\hline \multicolumn{11}{|c|}{ Direct effects } \\
\hline & $\gamma$ & $t$-stat & $\gamma$ & $t$-stat & $\gamma$ & $t$-stat & $\gamma$ & $t$-stat & $\gamma$ & $t$-stat \\
\hline \multicolumn{11}{|c|}{ on currency } \\
\hline by $r$ & -0.47 & $-3.02^{*}$ & -0.24 & $-2.28^{* *}$ & -0.38 & $-4.72^{*}$ & -0.45 & $-3.56^{*}$ & -0.20 & $-1.77^{\dagger}$ \\
\hline \multicolumn{11}{|c|}{ on labor force } \\
\hline by $\delta$ & 0.02 & 0.17 & -0.13 & $-1.61^{\dagger}$ & -0.04 & -0.47 & 0.00 & 0.00 & -0.14 & $-2.59^{*}$ \\
\hline by $g$ & 0.38 & $2.84^{*}$ & 0.21 & $2.76^{*}$ & 0.09 & 1.10 & 0.07 & 0.85 & 0.25 & $1.93^{\dagger}$ \\
\hline by $r$ & -0.36 & $-2.85^{*}$ & -0.05 & -0.59 & -0.06 & -0.61 & -0.10 & -1.38 & -0.02 & -0.23 \\
\hline
\end{tabular}

The group results in the latter regime are presented in Table 5 . There are again significant direct effects. For this period, the estimated coefficient for the growth of currency is 0.202 with the $t$-statistics of 1.093 and that for the growth of labor force participation rate is 0.288 with the $t$-statistics of 2.943 . Comparing these results, the $\beta^{\prime} s$ change remarkably from one regime to another; the labor force participation rate increases its weight compared with that of the currency.

We present the results for Mediterranean group with a caution, as the estimation routine sent a warning that the psi matrix is not positive definite for this group. The latent variable $R^{2}$ 's for the other country groups are as follows: 0.31 for the German region, 0.70 for northern Europe, 0.83 to the Rest of Europe and 0.58 for the Rest of the World.

We first notice that the taxation variable has a positive and significant effect on the shadow economy in all of our groups. Compared with the results of the first regime, the magnitude of the coefficient of the tax variable has increased and it has become statistically more significant. We take this as an indication of the worsening of the tax morale across all of the groups. Moreover, the transfer payments have a negative and significant effect in the German area, in the Mediterranean countries and in the Rest of the World. It appears as a robust finding in these groups that the transfer payments indeed tend to decrease the size of the shadow economy. Their role is, however insignificant in the Nordic countries and in the Rest of Europe, but perhaps for different reasons. Instead, the government consumption tends to increase the shadow activity in those two country groups. Lastly, we note that the shadow economy is increasing in the crime rate in the North whilst it appears to be decreasing in the crime rate in the Rest of the World. The former might be due that an increase in the crime rate truly reflects increased crime, whilst the latter might reflect increased crime reporting and/or probability of getting caught.

The opportunity cost of holding money has lost much of its importance in the latter period. This could be the indication that as the official economy has gained more options 
for the means of payments, the currency has gone more underground.

Table 5: Group estimates in the second regime 1992-2003.

\begin{tabular}{|c|c|c|c|c|c|c|c|c|c|c|}
\hline \multirow{2}{*}{\begin{tabular}{|l|} 
Cause \\
\end{tabular}} & \multicolumn{2}{|l|}{ GER } & \multicolumn{2}{|l|}{$\mathrm{PN}$} & \multicolumn{2}{|l|}{$\mathrm{CS}$} & \multicolumn{2}{|l|}{ RoE } & \multicolumn{2}{|l|}{ RoW } \\
\hline & & & & & & & & & & \\
\hline & $\alpha$ & $t$-stat & $\alpha$ & $t$-stat & $\alpha$ & $t$-stat & $\alpha$ & $t$-stat & $\alpha$ & $t$-stat \\
\hline$\tau$ & 0.10 & $2.12^{* *}$ & 0.21 & $3.81^{*}$ & 0.20 & $4.75^{*}$ & 0.32 & $4.18^{*}$ & 0.24 & $5.45^{*}$ \\
\hline$\delta$ & -0.23 & $-4.68^{*}$ & -0.15 & -1.53 & -0.14 & $-2.18^{* *}$ & -0.12 & -1.32 & -0.12 & $-2.41^{* *}$ \\
\hline$g$ & 0.06 & 1.22 & 0.13 & $2.10^{* *}$ & 0.03 & 0.62 & 0.27 & $2.96^{*}$ & 0.11 & 1.60 \\
\hline$k$ & 0.02 & 1.32 & 0.04 & $1.85^{\dagger}$ & 0.03 & 1.10 & -0.03 & -1.47 & -0.05 & $-2.41^{* *}$ \\
\hline$r$ & 0.05 & 0.44 & -0.17 & $-1.65^{\dagger}$ & -0.18 & $-3.41^{*}$ & -0.06 & -0.61 & -0.15 & $1.89^{\dagger}$ \\
\hline \multicolumn{11}{|c|}{ Direct effects } \\
\hline & $\gamma$ & $t$-stat & $\gamma$ & $t$-stat & $\gamma$ & $t$-stat & $\gamma$ & $t$-stat & $\gamma$ & $t$-stat \\
\hline \multicolumn{11}{|c|}{ on currency } \\
\hline by $r$ & -0.54 & -1.26 & 0.05 & 0.25 & -0.22 & $-1.98^{* *}$ & -0.30 & -0.99 & 0.10 & 0.79 \\
\hline \multicolumn{11}{|c|}{ on labor force } \\
\hline by $\delta$ & 0.01 & 0.14 & -0.22 & $-1.81^{\dagger}$ & -0.01 & -0.13 & -0.21 & $-3.42^{*}$ & -0.08 & $-1.76^{\dagger}$ \\
\hline by $g$ & -0.06 & -1.49 & 0.20 & $2.23^{* *}$ & 0.06 & 0.65 & 0.17 & $2.98^{*}$ & 0.07 & 1.12 \\
\hline by $r$ & -0.14 & -1.39 & -0.25 & $-2.46^{* *}$ & 0.00 & 0.00 & 0.02 & 0.34 & -0.10 & -1.42 \\
\hline
\end{tabular}

Our results appear to contradict those of Alm and Torgler (2005) who suggest that southern Europeans have lower tax morale than the Northern Europeans. In the latter period, the estimated coefficients of the tax variable are virtually the same. Yet, the tax morale, however, seems to differ somewhat across the group of countries, being the worst in the Rest of Europe.

Comparing our pooled results with our grouped results, especially with regard to the public sector variables, we find that pooling is inappropriate. For example, in the first regime the coefficient of transfer payments variable varies from -0.13 to -0.44 , whilst the pooled estimate is -0.25 . Clearly the pooled estimate is a bad approximation for the German region and for Mediterranean countries. When calibrating the size of the shadow economy, these differences may severely distort the results obtained. This is true for other variables as well.

Lastly, based on our results we can argue that the regime is an important aspect when analyzing the evolution of shadow economy. There are significant changes in the parameter estimates when moving from one regime to another. For example, in the case of the Nordic countries, the transfer payments are significant in the first period but insignificant in the latter. The change in the parameter estimates is remarkable in absolute value. There are similar differences between regimes for other country groups as well.

\section{Final Remarks}

The econometric results provide support for the proposed causes of shadow economies. Taxation, government consumption and social security variables (transfer payments) were all found significant. As a policy implication, this finding suggests that an increase in the size of the public sector with the high tax burden has side-effects: hidden economy expands. 
Such an implication provides support for the view that by controlling the tax burden, tax competition also creates brakes for shadow economies while the tax harmonization may have the opposite effect. The significant negative coefficient of the state transfer variable points to the possibility that the transfers might operate like a bribe on people, persuading them out of the shadow economy. On the other hand, our evidence on tax morale suggests that its effect on hidden economy has increased. We take this as an indication of worsening on tax morale. The econometric success with the crime rate as the proxy of morale in control of the shadow economy was, however, limited. Moreover, also the opportunity cost of money has an impact on the shadow economy.

If one was to calibrate a tentative index on the size of the shadow economy based on our results, it would be apparent that three important empirical results are found in this paper. Firstly, direct effects are significant. Secondly, pooling is clearly wrong and thirdly, regime switches are important. In line with Breusch $(2005 \mathrm{a}, \mathrm{b})$ we conclude that calibrating the index to the size of the shadow economy is hazardous as there are many sources for errors. 


\section{A Data Definitions}

Table B1 lists the variables used in this study. The definition in column 3, is the shortened name of the variable, which is referred to at the text. Column 2 "Transformation" explains the operations and transformations that were executed. Column 4 "Source" defines the primary source of the data.

Table B1: List of the variables and their sources.
\begin{tabular}{|llll|}
\hline Variable & Transformation & Definition & Sources \\
\hline$p$ & & Inflation rate per annum & OECD \\
$r$ & $\log (1+r)$ & Short-term market interest rate & OECD \\
$x$ & $d \log \left(\frac{G D P}{s} / p o p\right)$ & Real GDP per capita & OECD \\
$m$ & $d \log \left(\frac{m}{P} / p o p\right)$ & Real Currency in circulation, per capita & OECD/IMF \\
$l$ & $d \log (l)$ & Labour force participation rate & OECD \\
$t$ & $d \log (t)$ & Transfer payments ${ }^{14}$ & OECD \\
$g$ & $d \log (g)$ & Goverment consumption & OECD \\
$\tau$ & $d \log (\tau)$ & Tax revue (direct + indirect) & OECD \\
$k$ & $d \log \left(\frac{k}{p o p}\right)$ & Crime rate & Many 15 \\
$G D P$ & & Nominal gross domestic product & OECD \\
$p o p$ & & Population of country & OECD \\
$P$ & & Consumer price index & OECD \\
$s$ & & GDP deflator & OECD \\
\hline
\end{tabular}

\section{B Description On Fit-Indices and Elimination of Direct Ef- fects}

The $\chi^{2}$-test suggests a good fit if the $p$-value is larger than 0.05 . The contrary is true for the baseline model comparison $\chi^{2}$-test. The $\chi^{2}$-test statistic is affected by factors, such as the sample and the model sizes. Hence we also report TLI (Tucker-Lewis Index) test, which tests the null of no latent variables against the alternative of latent variables existing. The conventional cutoff value for TLI has been 0.9 and it is relatively unaffected by sample size (Bollen 1990). The interpretation of CFI (Bentler's Comparative Fit Index) is similar to that of TLI but it appears to be affected by the sample size as well as non-normality of the data. SRMR values smaller than 0.05 indicate that the fit of the model is good.

To identify the model and the parameter estimates, we resort to the perceived economic theory as much as it is off guidance. Therefore, we choose to assume that direct effects from the crime rate on our indicator variables are zero. We impose the restriction $\beta_{1}=1$, which suggest that an increase in shadow economy increase real GDP per capita, both in growth terms. To summarize, we begin to identify our model by imposing restrictions $\gamma_{j 4}=0$ for $j=1,2,3, \beta_{1}=1$. Then identifying the "true" model we proceed as follows.

First, we test the direct effects from our four remaining cause variables at the labor

\footnotetext{
${ }^{14}$ Missing observations for Switzerland.

${ }^{15}$ See SourceOECD, European Sourcebook of Crime and Criminal Justice Statistics 2003 and national Bureaus of Statistics.
} 
force participation rate. It appears that all of them, with the exception of the tax variable, are significantly different from zero. Hence, we drop the tax variable and re-estimate the model. The next step is to estimate the direct effects on GDP. We thus add four cause variables on the equation of the GDP-variable and re-estimate. All direct effects turn out to be insignificant. We drop them one by one until they have all been removed from the model. Lastly, we add the direct effects on the money. The direct effect of the interest rate variable on the money appears significant, as also suggested by monetary theory hence we keep it. Most interesting, no evidence, however, is found to support the view that the tax morale differs between the Catholic South and Protestant North in Europe. This suggest that homo oeconomicus and homo moralis are more similar across populations than often believed. 


\section{References}

[1] Aigner, D.J. and Goldberger, A.S. (1979), Contributions to Economic Analysis, NorthHolland Publishing Company

[2] Aigner, D. and Schneider, F. and Ghosh, D. (1988), "Me and My Shadow: Estimating the Size of the U.S. Hidden Economy from Time Series Data", in Barnett, W.A. and Berndt, E.R. and White, H. (Eds.), Dynamic Econometric Modeling (pp. 297-334), Cambridge University Press.

[3] Aigner, D.J. ad Hsiao, C. and Kapteyn, A. and Wansbeek, T. (1984), "Latent Variable Models in Econometrics" in Griliches, Z and Intriligator, M.D., Handbook of Econometrics vol II, (pp. 1323-1393), North-Holland.

[4] Alm, J. and Torgler, B. (2006), "Culture Differences and Tax Morale in the United States and in Europe", Journal of Economic Psychology, 27, 2, 224-246.

[5] Allingham, M.G. and Sandmo, A. (1972), "Income Tax Evasion: A Theoretical Analysis", Journal of Public Economics, 1, 323-328.

[6] Anderberg, D. (2006), "A Dynamic Model of the Black Economy", FinanzArchiv, 61, $4,447-461$.

[7] Angrist, J.D. and Imbens, G.W. and Rubin, D.B., "Identification of Causal Effects Using Instrumental Variables", Journal of the American Statistical Association, 91, 434, 444455 .

[8] Baldry, Jonathan C. (1987), "Income Tax Evasion and the Tax Schedule: Some Experimental Results", Public Finance, 42, 3, 357-383.

[9] Binmore, K. (1998), Game Theory and the Social Contract II. Just Playing, Cambridge, Mass: The MIT Press.

[10] Brekke, K.A and Kvaerndokk, S. and Nyborg, K. (2003), "An Economic Model of Moral Motivation", Journal of Public Economics, 87, 1967-1983.

[11] Breusch, T. (2005a), "The Canadian Underground Economy: An Examination on Giles and Tedds", Canadian Tax Journal, vol 53, 2, 367-391.

[12] Breusch, T. (2005b), "Estimating the Underground Ecnomy using MIMIC Models", Economics WP, The Australian National University, November 2005.

[13] Cohen, L.E., and Machalek, R. (1988), "A General Theory of Expropriative Crime: An Evolutionary Ecological Approach", American Journal of Sociology, 94, 465-501.

[14] Council of Europe (2003), European Sourcebook of Crime and Criminal Justice Statistics - 2003. Council of Europe, Committee of Experts. Second Edition, WODC.

[15] Davidson, C., Martin, L., and Wilson, J.D. (2003), "Efficient Black Markets", CESifo Area Conference, mimeo. 
[16] Dell'Anno R. and Schneider, F. (2003), "The Shadow Economy of Italy and Other OECD Countries: What do we Know?", Journal of Public Finance and Public Choice, vol 21, 2-3, 97-120.

[17] Falkinger, J.(1995), "Tax Evasion, Consumption of Public Goods and Fairness", Journal of Economic Psychology, 16, 64-72.

[18] Fehr, E. and Gächter, S., (1998), "Reciprocity and Economics: The Economic Implications of Homo Reciprocans", European Economic Review, 42, 845-859.

[19] Fehr, E. and Gächter, S., (2002), "Altruistic Punishment in Humans", Nature, 415, $137-140$

[20] Frank, R. (1987), "If Homo Economicus Could Choose His Utility Function, Would He Want One with a Conscience", The American Economic Review, 1987, 593-604.

[21] Frank, R. (1988), Passions Within Reason. The Strategic Role of the Emotions, New York: W.W.Norton \& Company, Inc.

[22] Franks, D.D. and Marolla, J. (1976), "Efficacious Action and Social Approval as Interacting Dimensions of Self-Esteem: A Tentative Formulation Through Construct Validation", Sociometry, 39, 4, 324-341

[23] Fortin, B. and Lcaroix, G and Villeval, M-C (2004), "Tax Evasion and Social Interactions", IZA Discussion Paper N:o 1359. The institute for the Study of Labor.

[24] Frey, B. S. and Weck-Hanneman, H. (1984), "The Hidden Economy as an 'Unobserved' Variable", European Economic Review, 26, 33-53.

[25] Giles, , D.E. A. and Tedds, L.M. (2002) "Taxes and the Canadian Underground Economy", Canadian Tax Paper no. 106, Canadian Tax Foundation 2002.

[26] Goldberger, A.S. (1972), "Structural Equation Methods in the Social Sciences", Econometrica, 40, 6, 979-1001.

[27] Gordon, J.P.F. (1989), "Individual Morality and Reputation Costs as Deterrants to Tax Evasion", European Economic Review, 33, 797-805.

[28] Grossman, H.I. (2002), "Make Us a King: Anarchy, Predation, and the State", European Journal of Political Economy, 18, 31-46.

[29] Hamilton, W. D. (1964), "The Genetic Theory of Social Behavior", Journal of Theoretical Biology 7, 1-32.

[30] Hausman D. M. and McPherson, M. S. (1993), "Taking Ethics Seriously: Economics and Contemporary Moral Philosophy", Journal of Economic Literature, 31, No.2, 671-731.

[31] Hill, R. (2002), "The Underground Economy in Canada: Boom or Bust?", Canadian Tax Journal, vol 50, 5, 1641-1654. 
[32] Im, K.S. and Pesaran, M. H. and Shin, Y. (2003), "Testing for Unit Roots in Heterogenous Panels", Journal of Econometrics, 115, 53-74.

[33] Johansson-Steinman, O. and Martinsson, P. (2005), "Honestly, Why are You Driving a BMW?", Journal of Economic Behavior \& Organization, forthcoming.

[34] Jöreskog, K. G. and Goldberger, A. S. (1975), "Estimating of a Model with Multiple Indicators and Multiple Causes of a Single Latent Variable", Journal of American Statistical Association, 70, 351, 631-639.

[35] Kandori, M. (1992), "Social Norms and Community Enforcement", Review of Economic Studies, 59, 63-80.

[36] Keiding, N. and Morgan, B. and Speed, T. and van der Heijden, P. (2004), Generalized Latent Variable Modeling: Multilevel, Longitudinal, and Structural Equations Models, Chapman and Hall.

[37] Kirchgässner, G. (1999), "Schattenwirtschaft und Moral: Anmerkungen aus Ökonomischer Perspektive". In S. Lamnek and J. Luedtke (Eds.), Der Sozialstaat Zwischen "markt" und "hedonismus"?, pp, 425-445, Westdeutscher Verlag.

[38] Levin, A.and Lin, C.-F. (1993), "Unit Root Tests in Panel Data: New Results", University of California at San Diego, Economics Working Paper Series No. 93-56.

[39] Macaulay, S. (1963), "Non-Cotractual Relations in Business: A Preliminary Study", American Sociological Review, 28, 55-67.

[40] Myles, G.D. and Naylor, R.A. (1996), "A Model of Tax Evasion with Group Conformity and Social Customs", European Journal of Political Economy, 12, 49-66.

[41] Orvaska, M and Hudson, J. (2002), "Tax Evasion, Civic Duty and the Law Abiding Citizen", European Journal of Political Economy, 19, 83-102.

[42] Schneider, F. (2004) "The Size of the Shadow Economies of 145 Countries all over the World: First Results over the Period 1999 to 2003", IZA DP No. 1431, December 2004.

[43] Schumacker, R.E. and Lomax, R.G. (2004), A Beginner's Guide to Structural Equation Modeling, Lawrence Erlbaum Associates.

[44] Smith, R. (2002), "The Underground Economy: Guidance for Policy Makers?", Canadian Tax Journal, vol 50, 5, 1655-1661.

[45] Steinen, I. and Schram, A. (2006), "Social Status and Group Norms: Indirect Reciprocity in a Repeated Helping xperiment", European Economic Review, forthcoming.

[46] Trivers, R. (1971), "The Evolution of Reciprocal Altruism", Quarterly Review of Biology, 46, 35-57.

[47] Vila, B.J., and Cohen, L.E. (1993), "Crime as Strategy: Testing an Evolutionary Ecological Theory of Expropriation Crime", American Journal of Sociology, 98, 873-912. 
[48] Wansbeek, T. and Meijer, E. (2001), "Measurement Error and Latent Variables", in Baltagi, Badi H. A Companion to Theoretical Econometrics, Blackwell Publishers Ltd, pp. 162-179.

[49] Weber, M. (1904), The Protestant Ethic and the Spirit of Capitalism. Tübingen.

[50] Weck, H. (1983), "Schattenwirtschaft: Eine Möglichkeit zur Einschränkung der öffentlichen Verwaltung?", Eine Ökonomische Analyse, Finanzwissenschaftliche Schriften 22, Bern, Lang.

[51] Wilson, E. O. (1975), Sociobiology: The New Synthesis, Cambridge, Mass: Belknap Press of Harvard University Press.

[52] World Values Surveys 1990, 1995, 2000 and 2005.

[53] Zellner, A: (1970), "Estimation of Regression Relationships Containing Unobservable Variables", International Economic Review, 11, 441-454. 